\title{
Nonsteroidal anti-inflammatory drugs versus placebo for post- endoscopic retrograde cholangiopancreatography pancreatitis: a systematic review and meta-analysis
}

다(1)이우

\begin{abstract}
Authors Salesse ${ }^{2}$, Paulo Sakai ${ }^{1}$, Eduardo Guimarães Hourneaux De Moura ${ }^{1}$

Institutions

1 Hospital das Clínicas da Faculdade de Medicina da Universidade de São Paulo - HC/FMUSP, Gastrointestinal Endoscopy Unit, São Paulo, Brazil

2 Pontifícia Universidade Católica de São Paulo - PUC/SP, São Paulo, Brazil
\end{abstract}

Juan Pablo Román Serrano', Diogo Turiani Hourneaux de Moura', Wanderley Marques Bernardo', Igor Braga Ribeiro', Tomazo Prince Franzini ${ }^{1}$, Eduardo Turiani Hourneaux de Moura ${ }^{1}$, Vitor Ottoboni Brunaldi ${ }^{1}$, Marianne Torrezan

submitted 21.6.2018

accepted after revision 29.1.2019

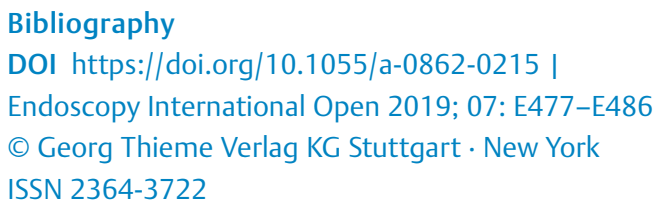

Corresponding author

Igor Braga Ribeiro, MD, 255 - Instituto Central - Prédio dos Ambulatórios - Pinheiros, Av. Dr. Enéas de Carvalho Aguiar, CEP: 05403-000 - São Paulo, SP, Brazil

Fax: +551130697579

igorbraga1@gmail.com

\section{ABSTRACT}

Background and study aims Endoscopic retrograde cholangiopancreatography (ERCP) is the primary therapeutic procedure for treatment of diseases that affect the biliary tree and pancreatic duct. While the therapeutic success rate of ERCP is high, the procedure can cause complications, such as acute pancreatitis (PEP), bleeding, and per- foration. This meta-analysis aimed to assess the efficacy of nonsteroidal anti-inflammatory drugs (NSAIDs) in preventing PEP following (ERCP).

Materials and methods We searched databases, such as MEDLINE, Embase, and Cochrane Central Library. Only randomized controlled trials (RCTs) that compared the efficacy of NSAIDs and placebo for the prevention of PEP were included. Outcomes assessed included incidence of PEP, severity of pancreatitis, route of administration, and type of NSAIDs.

Results Twenty-one RCTs were considered eligible with a total of 6854 patients analyzed. Overall, 3427 patients used NSAIDs before ERCP and 3427 did not use the drugs (control group). In the end, 250 cases of acute pancreatitis post-ERCP were diagnosed in the NSAIDs group and 407 cases in the placebo group. Risk for PEP was lower in the NSAID group (risk difference (RD): -0.05 ; $95 \%$ confidence interval $(\mathrm{Cl})$ : -0.07 to -0.03 ; number need to treat (NNT), $20 ; P<0.05)$. Use of NSAIDs effectively prevented mild pancreatitis compared with use of placebo (2.5\% vs. $4.1 \%$; $95 \%$ $\mathrm{Cl},-0.05$ to -0.01 ; NNT, 33 ; $P<0.05$ ), but the information on moderate and severe PEP could not be completely elucidated. Only rectal administration reduced incidence of PEP (6.8\% vs. $13 \%$; $95 \% \mathrm{Cl},-0.10$ to -0.04 ; NNT, $20 ; P<0.05$ ). Furthermore, only diclofenac or indomethacin use was effective in preventing PEP.

Conclusions Rectal administration of diclofenac and indomethacin significantly reduced risk of developing mild PEP. Further RCTs are needed to compare efficacy between NSAID administration pathways in prevention of PEP after ERCP.

\section{Introduction}

Endoscopic retrograde cholangiopancreatography (ERCP) is the primary therapeutic procedure for treatment of diseases that affect the biliary tree and pancreatic duct. While the therapeutic success rate of ERCP is high, the procedure can cause com- plications, such as acute pancreatitis (PEP), bleeding, and perforation [1].

PEP is the most common complication after ERCP. Previous studies estimate that their overall incidence after examination may range from $1 \%$ to $10 \%$ reaching an alarming $30 \%$ in cases of patients at high risk [2,3]. Stratification of degree of post-examination pancreatitis, based on previous statistics, demon- 


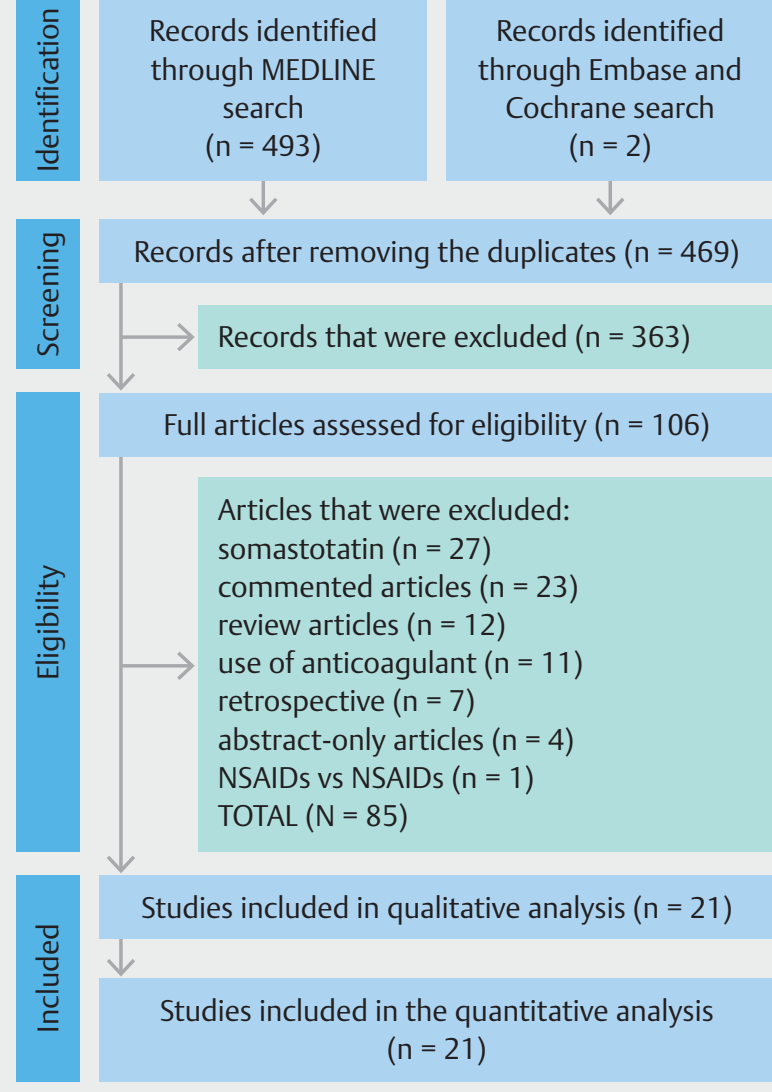

- Fig. 1 Selection of studies: PRISMA flowchart.

strates incidence rates of $3.6 \%$ to $4 \%$ for mild acute pancreatitis, $1.8 \%$ to $2.8 \%$ for moderate acute pancreatitis, and $0.3 \%$ to $0.5 \%$ for severe acute pancreatitis $[4,5]$.

Risk factors for PEP include sex (female), age (30 to 40 years), and history of dysfunction in the sphincter of Oddi, pancreatitis, and biliary tree obstruction $[1,2,6]$. PEP may increase hospitalization time, drug use, rate of intensive care unit (ICU) admission, and incidence of pancreatic necrosis and edema, pseudocyst formation, inflammation or sepsis, and death (1$3 \%$ of patients) [7]. Therefore, prevention of PEP is critical to increasing patient safety and reducing healthcare burden.

Numerous studies have examined preventative measures for PEP, such as use of nonsteroidal anti-inflammatory drugs (NSAIDs) and placement of pancreatic stents. NSAIDs inhibit activation of intrapancreatic proteases, thereby preventing inflammatory cascade and reducing pancreatic lesions $[8,9]$, whereas placement of a pancreatic stent is expected to maintain fluid secretion, which reduces papillary edema [10].

Over the years, numerous families of drugs have been used as prophylactic medications, ranging from protease inhibitors (Pis) to antibiotics, hormonal drugs, antioxidants, heparin and anti-inflammatory cytokines. Drugs used for prevention of acute PEP, including corticosteroids, have been tested [11].
Moreover, the PI aprotinin (Trasylol) was one of the first agents assayed for PEP [12], and the drug was widely used for PEP in the 1970 s and 1980 s.

In recent systematic reviews, it is worth noting that recommendations emphasized use of topical epinephrine for the sphincter of Oddi and sublingual nitroglycerin in addition to parallel prescriptions for aggressive use of intravenous fluids [11].

Use of indomethacin, aspirin, and other NSAIDs for treatment of acute pancreatitis has been investigated since the 1980 s [13]. Remarkably, indomethacin can induce PEP, although less frequently than cortisone [14].

Considering the anti-inflammatory properties of NSAIDs for papillary edema and PEP, along with controversies about prevention of PEP with use of pharmacologic interventions, we conducted a systematic review and meta-analysis.

The current study aimed to compare efficacy of NSAIDs versus placebo in prevention of acute PEP after ERCP.

\section{Materials and methods}

\section{Protocol and registry}

This systematic review and meta-analysis was performed in accordance with recommendations in the Cochrane Handbook, following the Preferred Reporting Items for Systematic Reviews and Meta-Analyses (PRISMA) [15]. The review was registered in PROSPERO international database under the number 42016049582.

\section{Eligibility criteria and search procedure}

Only randomized controlled trials (RCTs) that assessed use of NSAIDs in preventing PEP were included. There was no restriction with regard to language and date of publication. Studies including use of pancreatic stents were excluded. Patients older than 18 years who underwent their first ERCP were included. Studies with alternative groups of patients were excluded from the analysis. NSAIDs and placebo were administered in the RCTs.

The primary ouctome of the studies selected was incidence of PEP. Secondary outcomes were severity of pancreatitis (mild, moderate, and severe), route of administration (rectal, intramuscular [IM], intravenous [IV], and oral), and types of NSAIDs (indomethacin, diclofenac, and others).

We thoroughly searched databases, such as MEDLINE, Embase, and Cochrane Central Library, from the start of the study until October 1, 2017.

The keywords used in searching MEDLINE were as follows: (Retrograde Cholangiopancreatography, Endoscopic OR Cholangiopancreatographies, Endoscopic Retrograde OR Endoscopic Retrograde Cholangiopancreatographies OR Retrograde Cholangiopancreatographies, Endoscopic OR Endoscopic Retrograde Cholangiopancreatography OR ERCP) AND (Pancreatitis) AND (AINES OR Diclofenaco OR Indomethacin OR Naproxen). For other databases, we combined simpler terms, such as ERCP AND Pancreatitis AND NSAID.

Evaluation of eligibility criteria and selection of studies were performed independently by two reviewers. Any disagreement 
- Table 1 Study characteristics.

\begin{tabular}{|c|c|c|c|c|c|}
\hline Reference & Year & Country & Administration & Single dose & Type of NSAID \\
\hline Andrade et al. 2015 [28] & 2015 & México & Rectal & $100 \mathrm{mg}$ & Indomethacin \\
\hline Bhatia et al. 2011 [5] & 2011 & India & Intravenous & $20 \mathrm{mg}$ & Valdecoxib \\
\hline Cheon et al. 2007 [25] & 2007 & USA & Oral & $50 \mathrm{mg}$ & Diclofenac \\
\hline Döbrönte et al. 2014 [30] & 2014 & Hungary & Rectal & $100 \mathrm{mg}$ & Indomethacin \\
\hline Elmunzer et al. 2012 [14] & 2012 & USA & Rectal & $100 \mathrm{mg}$ & Indomethacin \\
\hline Hauser et al. 2016 [19] & 2016 & Croatia & Rectal & $100 \mathrm{mg}$ & Diclofenac \\
\hline Ishiwatari et al. 2016 [17] & 2016 & Japan & Oral & $100 \mathrm{mg}$ & Diclofenac \\
\hline Khoshbaten et al. 2008 [21] & 2008 & Irán & Rectal & $50 \mathrm{mg}$ & Diclofenac \\
\hline Leerhoy et al. 2016 [18] & 2016 & Denmark & Rectal & $100 \mathrm{mg}$ & Diclofenac \\
\hline Levenick et al. 2016 [29] & 2016 & USA & Rectal & $100 \mathrm{mg}$ & Indomethacin \\
\hline Lua et al. 2015 [15] & 2015 & Malaysia & Rectal & $100 \mathrm{mg}$ & Diclofenac \\
\hline Mansour et al. 2016 [32] & 2016 & Irán & Rectal & $500 \mathrm{mg}$ & Naproxen \\
\hline Montaño et al. 2007 [27] & 2007 & México & Rectal & $100 \mathrm{mg}$ & Indomethacin \\
\hline Mousalreza et al. 2016 [31] & 2016 & Irán & Rectal & $100 \mathrm{mg}$ & Indomethacin \\
\hline Murray et al. 2003 [24] & 2003 & Scotland & Rectal & $100 \mathrm{mg}$ & Diclofenac \\
\hline Otsuka et al. 2012 [23] & 2012 & Japan & Rectal & $50 \mathrm{mg}$ & Diclofenac \\
\hline Park et al. 2014 [16] & 2014 & Korea & Intramuscular & $100 \mathrm{mg}$ & Diclofenac \\
\hline Patai et al. 2015 [26] & 2015 & Hungary & Rectal & $100 \mathrm{mg}$ & Indomethacin \\
\hline Quadros et al. 2016 [33] & 2016 & Brazil & Intravenous & $100 \mathrm{mg}$ & Ketoprofen \\
\hline Senol et al. 2009 [20] & 2009 & USA & Intravenous & $50 \mathrm{mg}$ & Diclofenac \\
\hline Uçar et al. 2016 [22] & 2016 & Turkey & Intramuscular and rectal & $75-100 \mathrm{mg}$ & Diclofenac \\
\hline
\end{tabular}

was resolved by the authors after reaching a consensus. The selection process is outlined in the PRISMA flow chart [15].

Each study was classified according to risk of bias, which considered clinical questions, randomization, allocation, blinding, loss to follow-up, prognostic factors, outcomes, and intention to treat analysis. We also used the JADAD scale (Jadad et al. 1996) [16], which considers randomization, blinding of patients and investigators, and description of exclusion and losses.

\section{Data analysis}

Data were extracted based on intention to treat information. Absolute numbers, means and standard deviations were used for quantitative analysis. For every outcome and subgroup analysis, we calculated the RD with $95 \% \mathrm{Cl}$, and a $P<0.05$ was considered significant. Analyses were carried out using RevMan 5.3 software. Due to the heterogeneity of studies, a statistical analysis using a random effect model was performed.

\section{Results}

Twenty-one RCTs were considered eligible with a total of 6854 patients analyzed. Of the patients, 3427 used NSAIDs before ERCP (intervention) and 3427 did not use the drugs (control group) ( $\triangleright$ Fig. 1 ).

With regard to route of administration, NSAIDs were administered via the rectum, IV, IM, and per OS in 12, three, one, and twp studies, respectively. The following NSAIDs were used: diclofenac [17-28], indomethacin [11,29-34], naproxen [35], valdecoxib [8], and ketoprofen [36]. Study characteristics are outlined in $>$ Table 1.

In assessment of risk of bias, all articles presented adequate randomization, allocation, and blinding. Losses occurred in five RCTs. However, the value did not reach $20 \%$. In all studies, the JADAD score was above 3 , which is satisfactory for inclusion in this systematic review. The bias assessment summary is outlined in $>$ Table 2.

Time to diagnose in individuals with PEP varied among studies from 90 minutes to 72 hours post-ERCP, and patients met at least two of the three major diagnostic criteria: history of abdominal pain, increase in amylase level, and imaging study results consistent with PEP. 
- Table 2 Descriptive table of the studies.

\begin{tabular}{|c|c|c|c|c|c|c|c|}
\hline Author & Randomization & Allocation & Blinding & Losses & Prognosis & IIT & JADAD \\
\hline Andrade et al. 2015 [28] & Yes & Yes & No & No & Homogeneous & Yes & 3 \\
\hline Bhatia et al. 2011 [5] & Yes & Yes & No & No & Homogeneous & No & 3 \\
\hline Cheon et al. 2007 [25] & Yes & Yes & Yes & Yes & Homogeneous & No & 5 \\
\hline Döbrönte et al. 2014 [30] & Yes & No & No & Yes & Homogeneous & No & 3 \\
\hline Elmunzer et al. 2012 [14] & Yes & Yes & Yes & No & Homogeneous & Yes & 5 \\
\hline Hauser et al. 2016 [19] & Yes & Yes & Yes & No & Homogeneous & Yes & 5 \\
\hline Ishiwatari et al. 2016 [17] & Yes & Yes & Yes & Yes & Homogeneous & No & 3 \\
\hline Khoshbaten et al. 2008 [21] & Yes & Yes & Yes & No & Homogeneous & No & 5 \\
\hline Leerhoy et al. 2016 [18] & Yes & No & No & No & Homogeneous & No & 3 \\
\hline Levenick et al. 2016 [29] & Yes & Yes & Yes & No & Homogeneous & Yes & 5 \\
\hline Lua et al. 2015 [15] & Yes & Yes & No & Yes & Homogeneous & Yes & 3 \\
\hline Mansour et al. 2016 [32] & Yes & Yes & Yes & No & Homogeneous & Yes & 4 \\
\hline Montaño et al. 2007 [27] & Yes & No & Yes & No & Homogeneous & No & 3 \\
\hline Mousalreza et al. 2016 [31] & Yes & Yes & Yes & No & Homogeneous & No & 3 \\
\hline Murray et al. 2003 [24] & Yes & Yes & Yes & No & Homogeneous & No & 3 \\
\hline Otsuka et al. 2012 [23] & Yes & No & No & No & Homogeneous & Yes & 3 \\
\hline Park et al. 2014 [16] & Yes & Yes & Yes & No & Homogeneous & No & 3 \\
\hline Patai et al. 2015 [26] & Yes & Yes & Yes & Yes & Homogeneous & Yes & 5 \\
\hline Quadros et al. 2016 [33] & Yes & Yes & Yes & No & Homogeneous & Yes & 5 \\
\hline Senol et al. 2009 [20] & Yes & No & No & No & Homogeneous & No & 3 \\
\hline Uçar et al. 2016 [22] & Yes & No & No & No & Homogeneous & Yes & 3 \\
\hline
\end{tabular}

\section{Incidence of post-ERCP pancreatitis}

All 21 articles assessed incidence of PEP and compared 3427 patients in each group. In total, 250 events were observed in the NSAID group and 407 in the control group. The RD was -0.05 ( $95 \% \mathrm{Cl},-0.07$ to $-0.03 ; P<0.05)$. The number needed to treat (NNT) was 20. Forest plots of the incidence of postERCP PEP are shown in > Fig. 2.

\section{Severity of pancreatitis}

Mild pancreatitis

Patients presented with mild pancreatitis in 14 of the 21 studies. In total, 136 of 2600 patients and 203 of 2569 patients in the NSAID and control groups, respectively, presented with the condition. Incidence of mild pancreatitis in the intervention group decreased, with an RD of $-0.03(95 \% \mathrm{Cl},-0.05$ to -0.01 ; $P<0.05)$. The NNT was 33 .

\section{Moderate pancreatitis}

Patients presented with moderate pancreatitis in 11 of 21 RTCs. In total, 54 of 2134 patients and 89 of 2150 patients in the NSAID and control groups, respectively, had the condition. The RD was $-0.01(95 \% \mathrm{Cl},-0.02$ to $0.00 ; P>0.05)$.

\section{Severe pancreatitis}

Patients presented with severe pancreatitis in seven of 21 studies. In total, 16 of 1740 patients and 23 of 1747 patients in the NSAID and control groups, respectively, had the condition. No statistical difference was observed between the methods with RD -0.00 ( $95 \% \mathrm{Cl},-0.01$ to $0.00 ; P>0.05)$.

Forest plots summarizing the analyses of the severity of the pancreatitis are shown in $>$ Fig. 3 .

\section{Routes of administration}

With regard to routes of drug administration, rectal administration was the most commonly used route. In 15 studies, 4988 patients preferred rectal administration. In total, 170 of 2492 patients in the NSAID group and 324 of 2496 patients in the control group presented with PEP. The RD was $-0.07(95 \% \mathrm{Cl}$, -0.10 to $-0.04 ; P<0.05)$. The NTT was 20 . 


\begin{tabular}{|c|c|c|c|c|c|c|c|c|}
\hline \multirow[b]{2}{*}{ Study or subgroup } & \multicolumn{2}{|c|}{ NSAIDs } & \multicolumn{2}{|c|}{ Placebo } & \multirow[b]{2}{*}{ Weight } & \multirow{2}{*}{$\begin{array}{c}\text { Risk difference } \\
\text { IV, random, } 95 \% \mathrm{CI}\end{array}$} & \multirow{2}{*}{\multicolumn{2}{|c|}{$\begin{array}{c}\text { Risk difference } \\
\text { IV, random, } 95 \% \mathrm{CI}\end{array}$}} \\
\hline & Events & Total & Events & Total & & & & \\
\hline Andrade et al., 2015 & 4 & 82 & 17 & 84 & $3.5 \%$ & $-0.15[-0.25,-0.06]$ & & \\
\hline Bhatia et al., 2011 & 12 & 127 & 12 & 127 & $4.8 \%$ & $0.00[-0.07,0.07]$ & & \\
\hline Cheon et al., 2007 & 17 & 105 & 17 & 102 & $3.4 \%$ & $-0.00[-0.11,0.10]$ & & \\
\hline Döbrönte et al., 2014 & 20 & 347 & 22 & 318 & $7.0 \%$ & $-0.01[-0.05,0.03]$ & & \\
\hline Elmunzer et al., 2012 & 27 & 295 & 52 & 307 & $5.9 \%$ & $-0.08[-0.13,-0.02]$ & - & \\
\hline Hauser et al., 2016 & 11 & 129 & 21 & 143 & $4.6 \%$ & $-0.06[-0.14,0.01]$ & & \\
\hline Ishiwatari et al., 2016 & 20 & 216 & 19 & 214 & $5.9 \%$ & $0.00[-0.05,0.06]$ & & \\
\hline Khoshbaten et al., 2008 & 2 & 50 & 13 & 50 & $2.3 \%$ & $-0.22[-0.35,-0.09]$ & & \\
\hline Leerhoy et al., 2016 & 28 & 378 & 49 & 394 & $6.7 \%$ & $-0.05[-0.09,-0.01]$ & & \\
\hline Levenick et al., 2016 & 16 & 223 & 11 & 226 & $6.5 \%$ & $0.02[-0.02,0.07]$ & & \\
\hline Lua et al., 2015 & 7 & 69 & 4 & 75 & $4.0 \%$ & $0.05[-0.04,0.14]$ & & \\
\hline Mansour et al., 2016 & 12 & 162 & 28 & 162 & $4.9 \%$ & $-0.10[-0.17,-0.03]$ & & \\
\hline Montaño et al., 2007 & 4 & 75 & 12 & 75 & $3.5 \%$ & $-0.11[-0.20,-0.01]$ & & \\
\hline Mousalreza et al., 2016 & 11 & 201 & 27 & 205 & $5.8 \%$ & $-0.08[-0.13,-0.02]$ & & \\
\hline Murray et al., 2003 & 7 & 110 & 17 & 110 & $4.3 \%$ & $-0.09[-0.17,-0.01]$ & & \\
\hline Otsuka et al., 2012 & 2 & 51 & 10 & 53 & $2.8 \%$ & $-0.15[-0.27,-0.03]$ & & \\
\hline Park et al., 2014 & 22 & 173 & 20 & 170 & $4.9 \%$ & $0.01[-0.06,0.08]$ & & \\
\hline Patai et al., 2015 & 18 & 270 & 37 & 269 & $6.1 \%$ & $-0.07[-0.12,-0.02]$ & & \\
\hline Quadros et al., 2016 & 5 & 224 & 5 & 253 & $7.6 \%$ & $0.00[-0.02,0.03]$ & & \\
\hline Senol et al., 2009 & 3 & 40 & 7 & 40 & $2.1 \%$ & $-0.10[-0.24,0.04]$ & & \\
\hline Uçar et al., 2016 & 2 & 100 & 7 & 50 & $3.4 \%$ & $-0.12[-0.22,-0.02]$ & & \\
\hline Total $(95 \% \mathrm{Cl})$ & & 3427 & & 3427 & $100.0 \%$ & $-0.05[-0.07,-0.03]$ & & \\
\hline Total events & 250 & & 407 & & & & & \\
\hline \multicolumn{9}{|c|}{ Heterogeneity: Tau $^{2}=0.00 ; \mathrm{Chi}^{2}=59.18, \mathrm{df}=20(P<0.00001) ; \mathrm{I}^{2}=66 \%$} \\
\hline \multicolumn{9}{|c|}{ Test for overall effect: $Z=4.05(P<0.0001)$} \\
\hline & & & & & & & $-0.2-0.10$ & 0.10 .2 \\
\hline & & & & & & & $\begin{array}{l}\text { Favours } \\
\text { [NSAIDs] }\end{array}$ & $\begin{array}{l}\text { Favours } \\
\text { [Placebo] }\end{array}$ \\
\hline
\end{tabular}

- Fig. 2 Forest plots on PEP incidence.

Six studies that used other administration routes (PO, IV, and IM) have reported that 80 of 935 patients and 83 of 931 patients in the NSAID and control groups, respectively, presented with PEP. The RD was -0.00 ( $95 \% \mathrm{Cl},-0.02$ to $0.02 ; P>0.05)$. Routes of administration and associated efficacies are summarized in > Fig. 4.

\section{Types of NSAIDs}

In 11 studies, diclofenac was used, and PEP was observed in 121 of 1421 patients in the NSAID group and 184 of 1403 patients in the control group. The RD was $-0.05(95 \% \mathrm{Cl},-0.09$ to -0.02 ; $P<0.05)$. The NTT was 20.

Seven RCTs evaluated efficacy of indomethacin in preventing PEP. In total, 100 of 1493 patients in the NSAID group and 178 of 1484 patients in the control group presented with PEP. The RD was $-0.06(95 \% \mathrm{Cl},-0.10$ to $-0.02 ; P<0.05)$ and the NNT was 17.

In three studies, other NSAIDs (valdecoxib, naproxen, and ketoprofen) were used for prevention of PEP. In total, 29 of 513 patients and 45 of 542 patients in the NSAID and control groups, respectively, presented with PEP. The RD was -0.03 ( $95 \% \mathrm{Cl},-0.09$ to $0.03 ; P>0.05$ ) and the NNT was 20 .

- Fig. 5 summarizes the meta-analysis on types of NSAIDs.

\section{Discussion}

The impact of periprocedural NSAIDs during ERCP has been extremely compelling within the last 4 to 5 years. Although the results were conflicting, major international societies have endorsed their routine prescription. The European Society of Comparative Gastroenterology recommends administering NSAIDs (diclofenac or indomethacin $100 \mathrm{mg}$ ) rectall before or after ERCP if no contraindications are observed [37]. Analogously, the American Society for Gastrointestinal Endoscopy [38] is in favor of administration of NSAIDs after contraindications have been ruled out. However, this is only applicable in high-risk individuals. Meanwhile, use of indomethacin for average-risk patients is also recommended.

As regards the Japanese Guidelines by the Japanese Ministry of Health, they advoacte a similar policy for intrarectal adminis- 


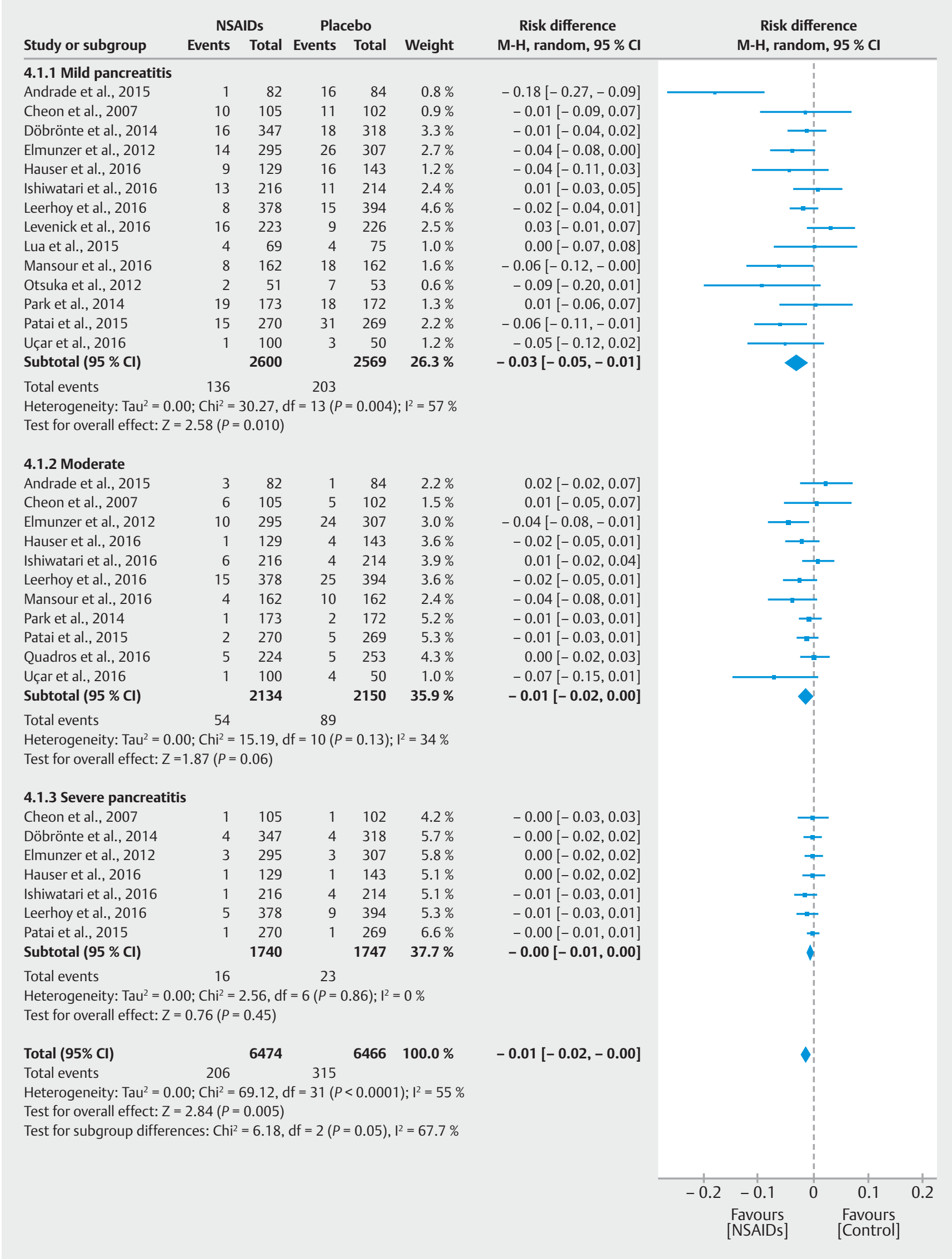

Fig. 3 Forest plots assessing NSAID efficacy according to pancreatitis severity. 


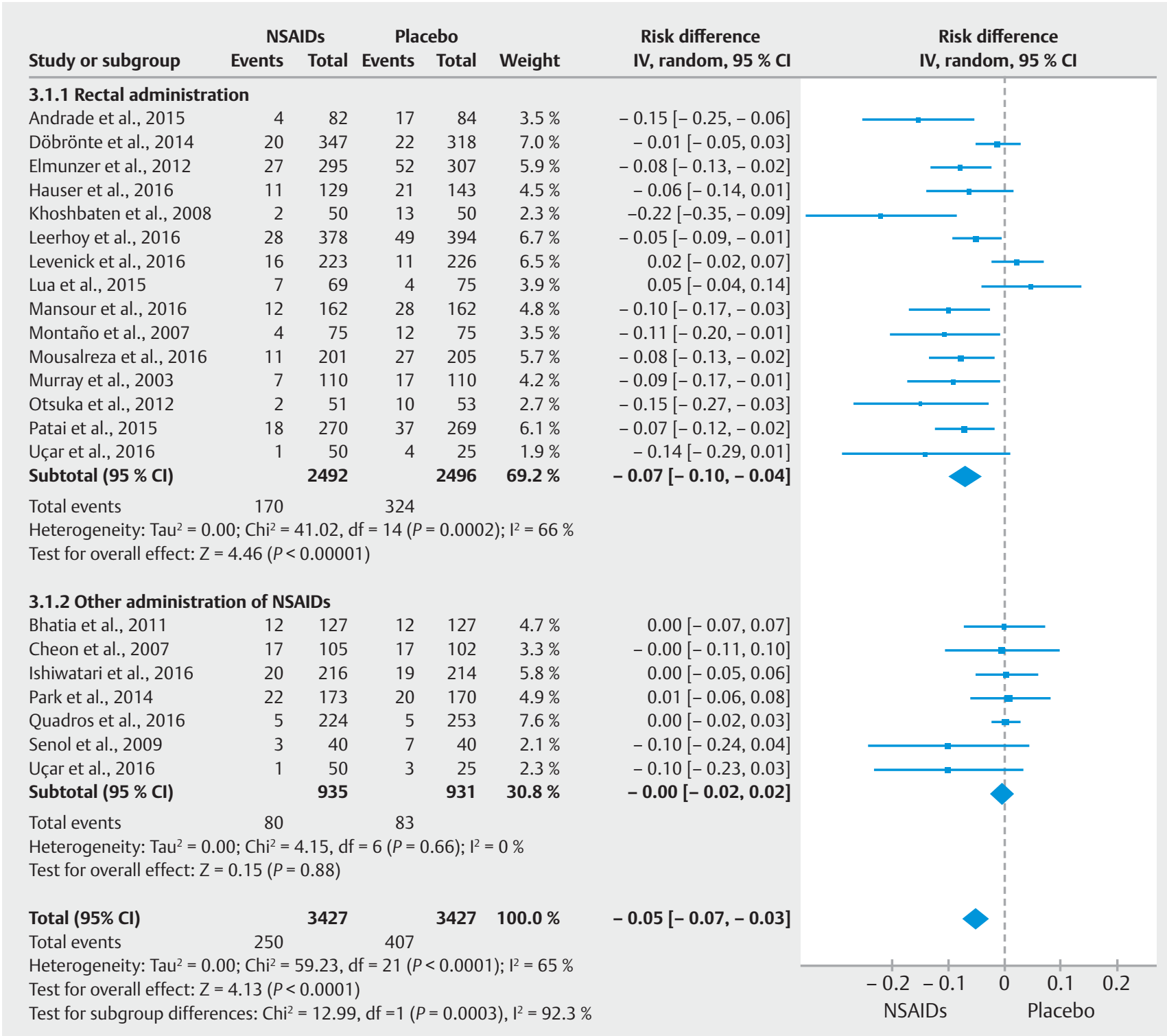

- Fig. 4 Forest plots assessing PEP according to route of drug administration and NSAID type.

tration of NSAIDs in all cases of ERCP with no contraindications [39]. The current study is based on these foundations with consideration for several unclear details.

Unlike other systematic reviews on use of NSAIDs to reduce risk of developing PEP $[3,40,41]$, the current study included only RCTs in which a subgroup analysis was conducted of the efficacy of such medications according to the severity of PEP, administration route, and drug type. Pooled results of these 21 randomized studies showed a significant reduction in risk of developing PEP with use of NSAIDs. However, the effect was restricted to mild cases. Furthermore, these studies showed the efficacy of rectal administration of diclofenac and indomethacin.

Due to the scarce number of randomized studies published in the literature, it was not possible to identify whether other NSAID administration routes are effective in preventing PEP be- yond the rectal route and we consider this a limitation of our study. Large RCTs and multicenter studies are needed comparing administration techniques for these NSAIDs as well as other different types of NSAIDs for evaluation and comparison of efficacy in preventing PEP post-ERCP.

Rectal administration of NSAIDs is the most commonly used method for preventing PEP. A standard recommended dose has not been established, although most studies used $100 \mathrm{mg}$ daily. Rectal administration of diclofenac or indomethacin using this dose is highly effective for prevention of PEP. Physicians performing ERCP will decide what drug to use. However, their decisions may also be influenced by cost because indomethacin is more expensive than diclofenac. A cost comparison of NSAIDs for decreasing incidence of PEP must be conducted.

To the best of our knowledge, this is the first meta-analysis on prevention of PEP with use of NSAIDs, which include all 


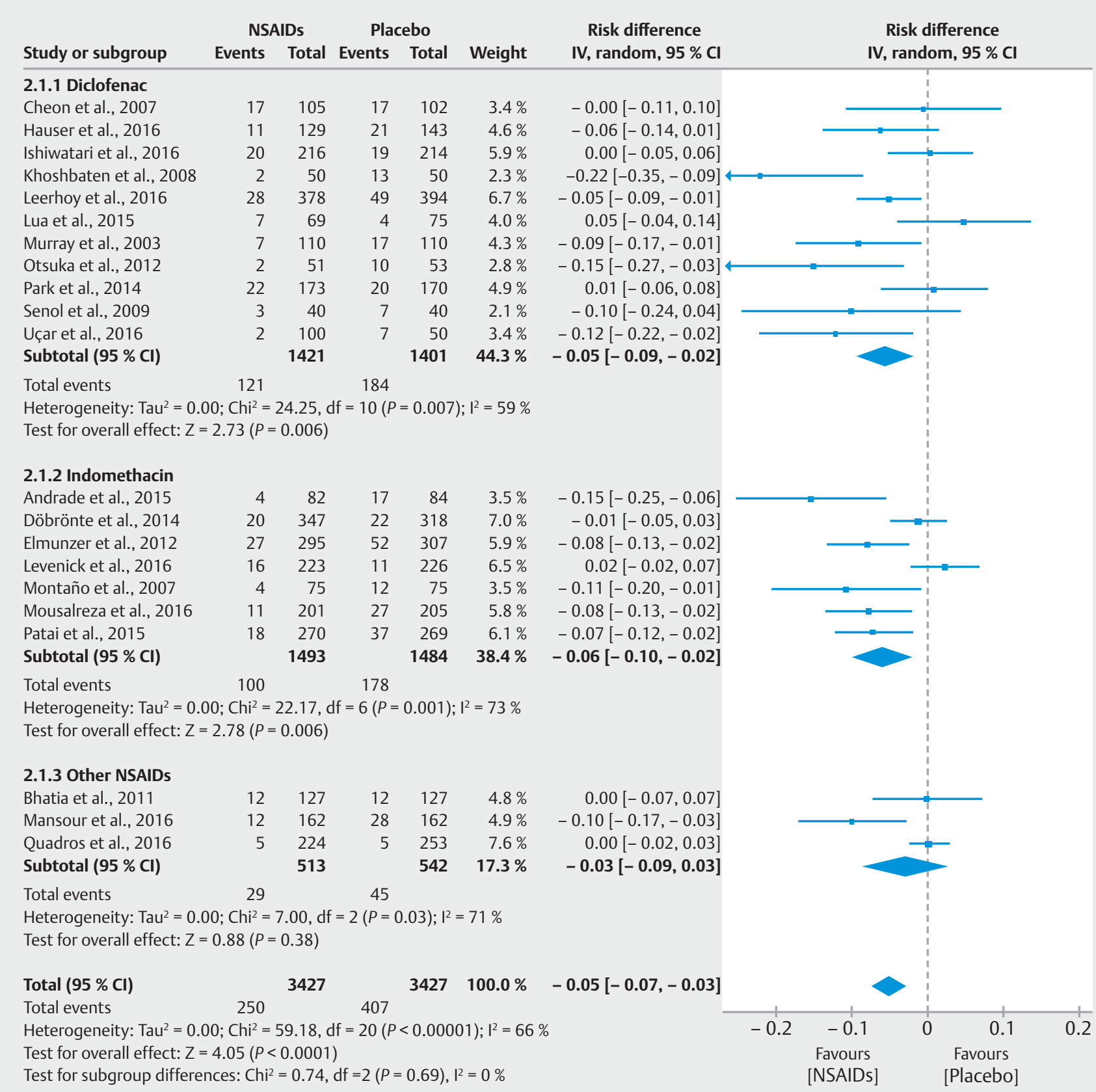

Fig. 5 Forest plots assessing types of NSAIDs used to prevent PEP.

types of such drugs (diclofenac, indomethacin, naproxen, valdecoxib, and ketoprofen). Both diclofenac and indomethacin are highly effective. The putative mechanism of action of these agents is inhibition of phospholipase A2, which leads to a decrease in the inflammatory cascade and downregulation of pro-inflammatory factors, such as leukotrienes, prostaglandins, and platelet-activating agents, and this mechanism reduced inflammatory lesions and organ necrosis $[8,9]$. Thus, lack of efficacy of other agents may result in reduced target inhibition with the dose used or pharmacokinetics that are disadvantageous. Nonetheless, the efficacy of other NSAIDs must be further investigated.
It is important to emphasize that our results may have been influenced by confounders, such as the experience of endoscopists, the endoscopic devices used, technical level and extent of nursing care, sedation method, and the type and amount of contrast agent used in the biliary tract. Moreover, several demographic factors influence risk of developing PEP, including sex (female), younger age, and obesity. Thus, patient sex ratio, age, and body mass index may have influenced overall incidence in the individual RCTs. Furthermore, risk for PEP increased with presence of specific diseases (dysfunction of the sphincter of Oddi, choledocholithiasis, biliary tract, and pancreatic tumors). Future studies must include both intervention 
and control groups. In addition, diagnosis of PEP and its changes post-ERCP showed a substantial heterogeneity among the studies, which included time of evaluation after the procedure (from 90 minutes to 72 hours), clinical symptoms (pain, nausea, and vomiting), and use of imaging data (tomography) $[11,18-36,41]$.

Another limitation of our manuscript was that not all RCTs stratified the degree of pancreatitis, and when they did, it was not standardized and uniform. A total of 657 cases of PEP was reported (with and without use of NSAIDs). For 521 patients, the degree of pancreatitis involvement was specified. In 339 of thse cases, patients were defined as having mild intensity pancreatitis, which represents a total of $65 \%$ of the stratified patients (339/521). Thus, our results demonstrated that NSAID use is superior for prevention inr patients who developed mild PEP post-ERCP.

Finally, the current systematic review focused only on incidence of PEP and its intensity. However, other complications that affect patient outcome after ERCP, such as perforations and bleeding, were not evaluated.

Nonetheless, this systematic review showed that rectal administration of diclofenac and indomethacin are effective in preventing acute PEP after ERCP. Compared to other methods used to prevent PEP, such as use of pancreatic stents [42, 43], NSAIDs are more convenient to administer, and such drugs are less expensive. Reducing incidence of PEP not only increases patient safety but also reduces healthcare burden by decreasing the rate of hospitalization and ICU stay.

\section{Conclusion}

Rectal administration of NSAIDs adequately reduces incidence of acute PEP after ERCP. Mild pancreatitis is the only preventable outcome. In this context, both diclofenac and indomethacin are considered effective. Further RCTs are needed to compare efficacy between NSAID administration pathways in prevention of acute pancreatitis after ERCP.

\section{Competing interests}

None

\section{References}

[1] Sajid MS, Khawaja AH, Sayegh M et al. Systematic review and metaanalysis on the prophylactic role of non-steroidal anti-inflammatory drugs to prevent post-endoscopic retrograde cholangiopancreatography pancreatitis. World J Gastrointest Endosc 2015; 7: 1341 - 1349

[2] Zhao ZH, Hu LH, Ren HB et al. Incidence and risk factors for post-ERCP pancreatitis in chronic pancreatitis. Gastrointest Endosc 2017; 86: 519-524.e1

[3] Sun HL, Han B, Zhai HP et al. Rectal NSAIDs for the prevention ofm post-ERCP pancreatitis: a meta-analysis of randomized controlled trials. Surgeon 2014; 12: $141-147$
[4] Freeman ML, DiSario JA, Nelson DB et al. Risk factors for post-ERCP pancreatitis: a prospective, multicenter study. Gastrointest Endosc 2001; 54: $425-434$

[5] Vandervoort ], Soetikno RM, Tham TC et al. Risk factors for complications after performance of ERCP. Gastrointest Endosc 2002; 56: 652 656

[6] Ferreira Ade F, Bartelega JA, Urbano HC et al. Acute pancreatitis gravity predictive factors: which and when to use them? Arq Bras Cir Dig 2015; 28: 207 - 211

[7] Nesvaderani M, Eslick GD, Vagg D et al. Epidemiology, aetiology and outcomes of acute pancreatitis: A retrospective cohort study. Int J Surg 2015; 23: $68-74$

[8] Bhatia V, Ahuja V, Acharya SK et al. A randomized controlled trial of valdecoxib and glyceryl trinitrate for the prevention of post-ERCP pancreatitis. J Clin Gastroenterol 2011; 45: 170-176

[9] Mäkelä A, Kuusi T, Schröder T. Inhibition of serum phospholipase-A2 in acute pancreatitis by pharmacological agents in vitro. Scand J Clin Lab Invest 1997; 57: $401-407$

[10] Choudhary A, Bechtold ML, Arif M et al. Pancreatic stents for prophylaxis against post-ERCP pancreatitis: a meta-analysis and systematic review. Gastrointest Endosc 2011; 73: 275 - 282

[11] Kubiliun NM, Adams MA, Akshintala VS. United States Cooperative for Outcomes Research in Endoscopy (USCORE). et al. Evaluation of Pharmacologic Prevention of Pancreatitis After Endoscopic Retrograde Cholangiopancreatography: A Systematic Review. Clin Gastroenterol Hepatol 2015; 13: 1231 -1239; quiz e70-1

[12] Brust R, Thomson AB, Wensel RH et al. Pancreatic injury following ERCP. Failure of prophylactic benefit of Trasylol. Gastrointest Endosc 1977; 24: $77-79$

[13] Olazabal A, Nascimento L. Effects of indomethacin, aspirin, and fatfree diet on experimental pancreatitis in the rat. J Lab Clin Med 1980; 96: $570-576$

[14] Guerra M. Toxicity of indomethacin. Report of a case of acute pancreatitis. JAMA 1967; 200: 552-553

[15] Moher D, Liberati A, Tetzlaff J et al. The PRISMA Group. Preferred Reporting Items for Systematic Reviews and Meta-Analyses: The PRISMA Statement. PLoS Med 2009; 6: e1000097 [https://doi.org/10.1371/ journal.pmed.1000097]

[16] Jadad AR, Moore RA, Carroll D et al. Assessing the quality of reports of randomized clinical trials: is blinding necessary? Control Clin Trials 1996; 17: $1-12$

[17] Elmunzer B], Scheiman JM, Lehman GA et al. U.S. Cooperative for Outcomes Research in Endoscopy (USCORE). A randomized trial of rectal indomethacin to prevent post-ERCP pancreatitis. N Engl J Med 2012; 366: $1414-1422$

[18] Lua GW, Muthukaruppan R, Menon J. Can rectal diclofenac prevent post endoscopic retrograde cholangiopancreatography pancreatitis? Dig Dis Sci 2015; 60: 3118-3123

[19] Park SW, Chung M], Oh TG et al. Intramuscular diclofenac for the prevention of post-ERCP pancreatitis: a randomized trial. Endoscopy 2015; 47: $33-39$

[20] Ishiwatari H, Urata T, Yasuda I et al. No benefit of oral diclofenac on post-endoscopic retrograde cholangiopancreatography pancreatitis. Dig Dis Sci 2016; 61: $3292-3301$

[21] Leerhøy B, Nordholm-Carstensen A, Novovic S et al. Effect of body weight on fixed dose of diclofenac for the prevention of post-endoscopic retrograde cholangiopancreatography pancreatitis. Scand J Gastroenterol 2016; 51: 1007-1012

[22] Hauser G, Blažević I, Salkić N et al. Diclofenac sodium versus ceftazidime for preventing pancreatitis after endoscopic retrograde cholangiopancreatography: a prospective, randomized, controlled trial. Surg Endosc 2017; 31: $602-610$ 
[23] Senol A, Saritas U, Demirkan H. Efficacy of intramuscular diclofenac and fluid replacement in prevention of post-ERCP pancreatitis. World J Gastroenterol 2009; 15: 3999-4004

[24] Khoshbaten M, Khorram H, Madad L et al. Role of diclofenac in reducing post-endoscopic retrograde cholangiopancreatography pancreatitis. J Gastroenterol Hepatol 2008; 23: e11-16

[25] Uçar R, Biyik M, Uçar E et al. Rectal or intramuscular diclofenac reduces the incidence of pancreatitis after endoscopic retrograde cholangiopancreatography. Turk J Med Sci 2016; 46: 1059-1063

[26] Otsuka T, Kawazoe S, Nakashita S et al. Low-dose rectal diclofenac for prevention of post-endoscopic retrograde cholangiopancreatography pancreatitis: a randomized controlled trial. J Gastroenterol 2012; 47: $912-917$

[27] Murray B, Carter R, Imrie C et al. Diclofenac reduces the incidence of acute pancreatitis after endoscopic retrograde cholangiopancreatography. Gastroenterology 2003; 124: 1786 - 1791

[28] Cheon YK, Cho KB, Watkins JL et al. Efficacy of diclofenac in the prevention of post-ERCP pancreatitis in predominantly high-risk patients: a randomized double-blind prospective trial. Gastrointest Endosc 2007; 66: $1126-1132$

[29] Patai Á, Solymosi N, Patai ÁV. Effect of rectal indomethacin for preventing post-ERCP pancreatitis depends on difficulties of cannulation: results from a randomized study with sequential biliary intubation. J Clin Gastroenterol 2015; 49: 429-437

[30] Montaño Loza A, Rodríguez Lomelí X, García Correa JE et al. Effect of the administration of rectal indomethacin on amylase serum levels after endoscopic retrograde cholangiopancreatography, and its impact on the development of secondary pancreatitis episodes. Rev Esp Enferm Dig 2007; 99: 330 - 336

[31] Andrade-Dávila VF, Chávez-Tostado M, Dávalos-Cobián C et al. Rectal indomethacin versus placebo to reduce the incidence of pancreatitis after endoscopic retrograde cholangiopancreatography: results of a controlled clinical trial. BMC Gastroenterol 2015; 15: 85

[32] Levenick JM, Gordon SR, Fadden LL et al. Rectal indomethacin does not prevent post-ercp pancreatitis in consecutive patients. Gastroenterology 2016; 150: 911 - 917; quiz e19

[33] Döbrönte Z, Szepes Z, Izbéki F et al. Is rectal indomethacin effective in preventing of post-endoscopic retrograde cholangiopancreatography pancreatitis? World J Gastroenterol 2014; 20: 10151-10157
[34] Hosseini M, Shalchiantabrizi P, Yektaroudy K et al. Prophylactic effect of rectal indomethacin administration, with and without intravenous hydration, on development of endoscopic retrograde cholangiopancreatography pancreatitis episodes: a randomized clinical trial. Arch Iran Med 2016; 19: 538-543

[35] Mansour-Ghanaei F, Joukar F, Taherzadeh Z et al. Suppository naproxen reduces incidence and severity of post-endoscopic retrograde cholangiopancreatography pancreatitis: Randomized controlled trial. World J Gastroenterol 2016; 22: 5114-5121

[36] de Quadros Onófrio F, Lima JCP, Watte G et al. Prophylaxis of pancreatitis with intravenous ketoprofen in a consecutive population of ERCP patients: a randomized double-blind placebo-controlled trial. Surg Endosc 2017; 31: 2317-2324

[37] Dumonceau JM, Andriulli A, Elmunzer BJ. European Society of Gastrointestinal Endoscopy. et al. Prophylaxis of post-ERCP pancreatitis: European Society of Gastrointestinal Endoscopy (ESGE) Guideline updated June 2014. Endoscopy 2014; 46: 799-815

[38] Chandrasekhara V, Khashab MA. ASGE Standards of Practice Committee. et al. Adverse events associated with ERCP. Gastrointest Endosc 2017; 85: $32-47$

[39] Yokoe M, Takada T, Mayumi T et al. Japanese guidelines for the management of acute pancreatitis: Japanese Guidelines 2015. J Hepatobiliary Pancreat Sci 2015; 22: 405-432

[40] Shi N, Deng L, Altaf K et al. Rectal indomethacin for the prevention of post-ERCP pancreatitis: A meta-analysis of randomized controlled trials. Turk J Gastroenterol 2015; 26: 236-240

[41] Li X, Tao LP, Wang CH. Effectiveness of nonsteroidal anti-inflammatory drugs in prevention of post-ERCP pancreatitis: a meta-analysis. World J Gastroenterol 2014; 20: 12322 - 12329

[42] de Moura ET, de Moura EG, Bernardo W et al. Guide wire-assisted cannulation versus conventional contrast to prevent pancreatitis. A systematic review and meta-analysis based on randomized control trials. Rev Gastroenterol Peru 2016; 36: 308 - 319

[43] Hwang H], Guidi MA, Curvale C et al. Post-ERCP pancreatitis: early precut or pancreatic duct stent? A multicenter, randomized-controlled trial and cost-effectiveness analysis Rev Esp Enferm Dig 2017; 109: $174-179$ 